

\section{La Cultura Mayangna. Una etnografía por imágenes}

Víctor Manuel del Cid Lucero

$\mathrm{E}$ 1 territorio indígena es más que un lugar para vivir. Es el lugar de origen [Batanhna], legado de los ancestros, donde conviven los seres humanos, los seres de la naturaleza y los seres espirituales [walasa]; la base de la organización social es la familia extensa [kalwanai]. Las comunidades y territorios mayangna encuentran en su cultura su fuerza [parasni] para permanecer y continuar viviendo en armonía [kalpakwi yalahna], que significa vivir en la unidad, paz, hermandad [kalwahai] entre todos sus miembros, compartiendo las riquezas materiales y espirituales.

La cultura mayangna, conformada por cuatro grupos etnolingüísticos: Panamahka, Tuahka, Yusku y Ulwa, ha sido determinada por los ríos, montañas y selvas, logrando desarrollar una vida sencilla de cazadores y recolectores. En nueve territorios indígenas mayangans, 8 en la Región Autónoma Caribe Norte y 1 en la Región Autónoma Caribe Sur, existen 78 comunidades Sumu-Mayangna. La mayoría están asentadas en las riberas de los ríos más caudalosos de la Costa Caribe: Waspuk, Wawa, Uliwas o cabecera de Prinzapolka, Umrawás, Walakwás o Lakus, Bambana, Amak-Bocay. Se organizan político-administrativamente comunidades y territorios, con una instancia de coordinación denominada Gobierno de la Nación Sumu-Mayangna.

Según el VIII Censo de Población y IV de Vivienda del 2005, los sumu-mayangna son 9,756 personas; sin embargo los censos propios de cada comunidad y territorio suman alrededor de 20,000 personas. 


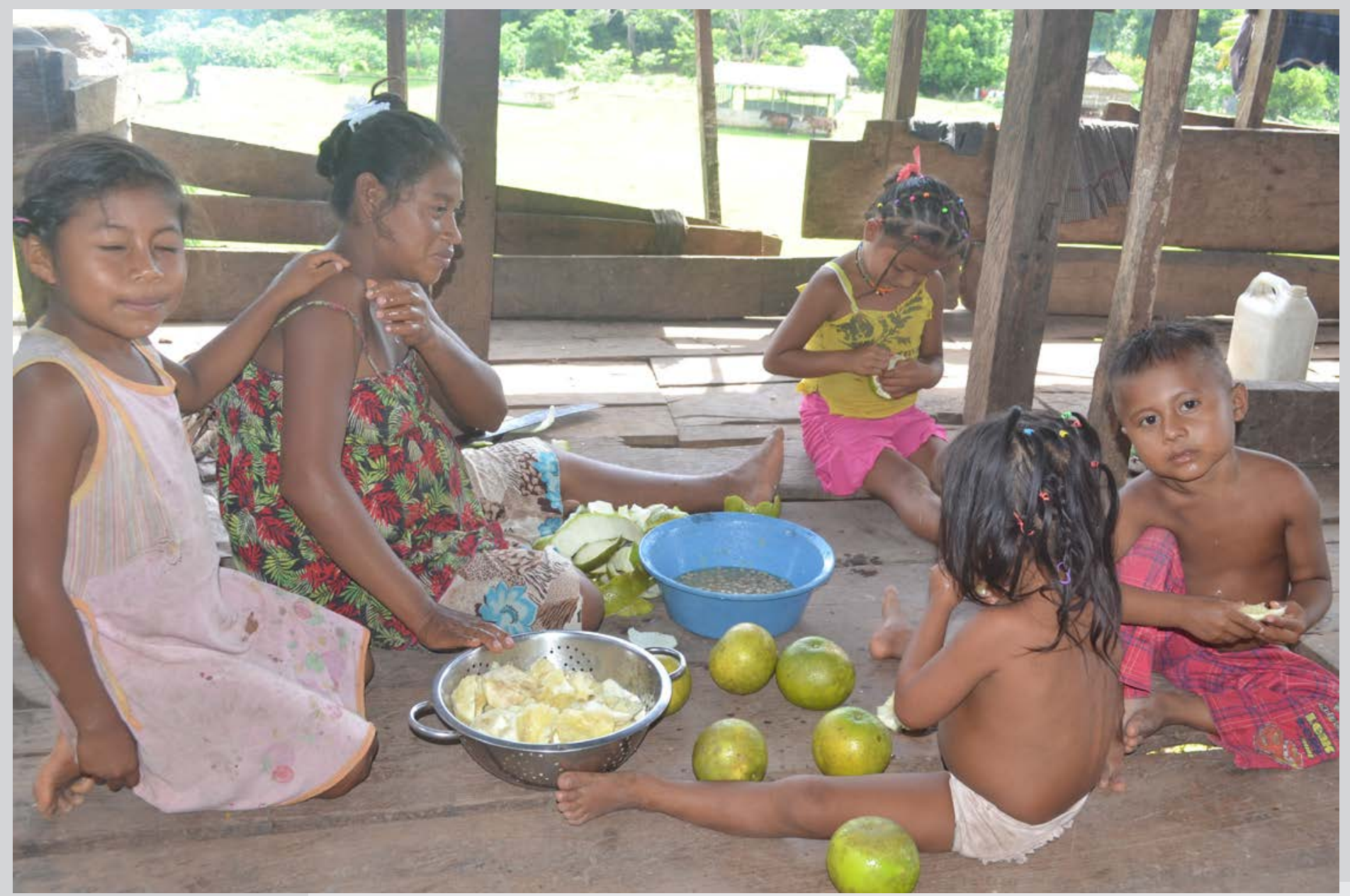

Familia comiendo naranjas. Comunidad de Sikilta. Territorio Mayangna Sauni Bas, Municipio de Siuna, 2015 (Foto: Del Cid) 
Señora Mayangna Panamahka, de la comunidad de Sakalwas, Territorio Mayangna Sauni As, Municipio de Bonanza, 2013 (Foto: Del Cid)

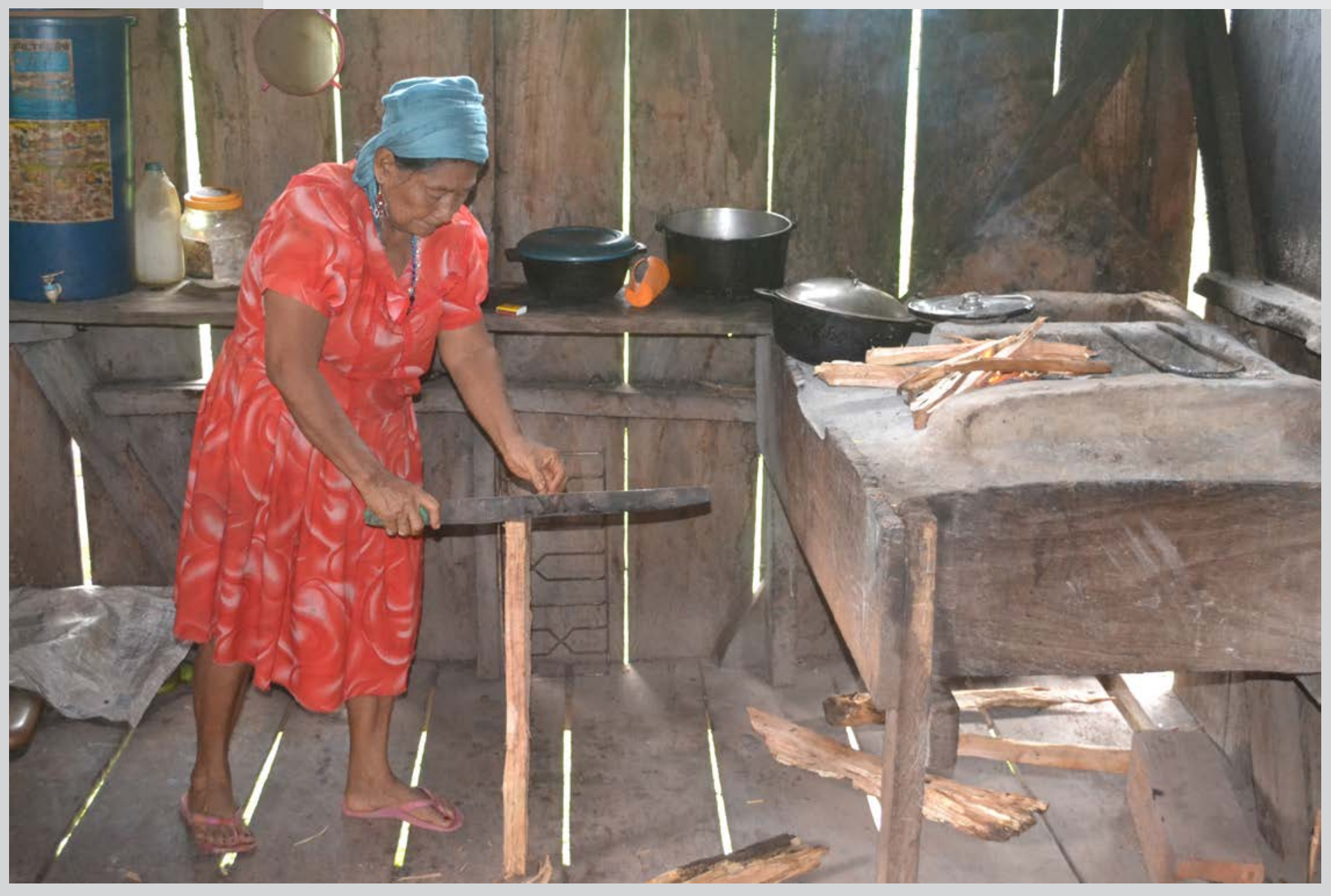




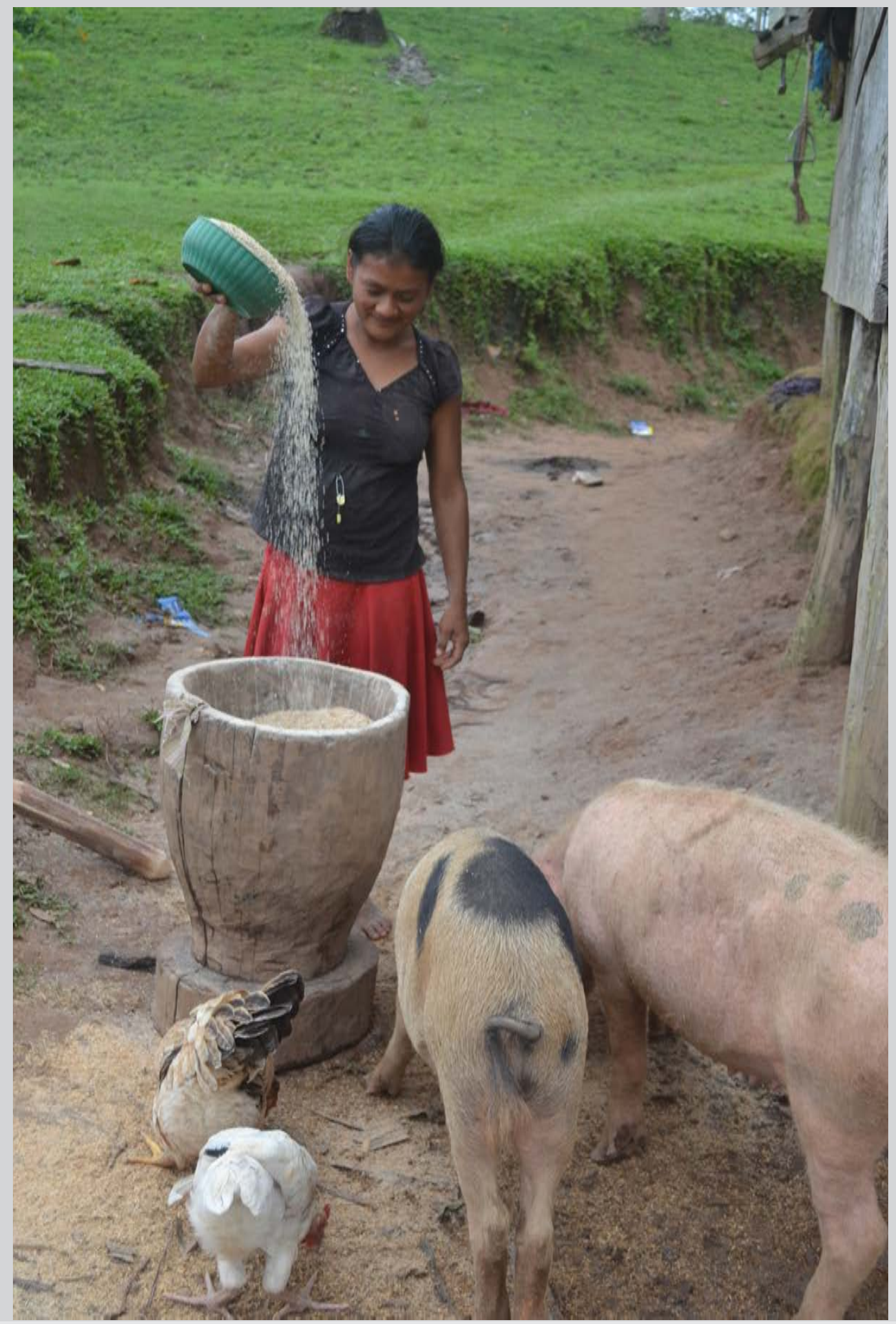

Señora pilando arroz en Sikilta, Territorio Mayangna Sauni Bas, Municipio de Siuna, 2015 (Foto: Del Cid) 


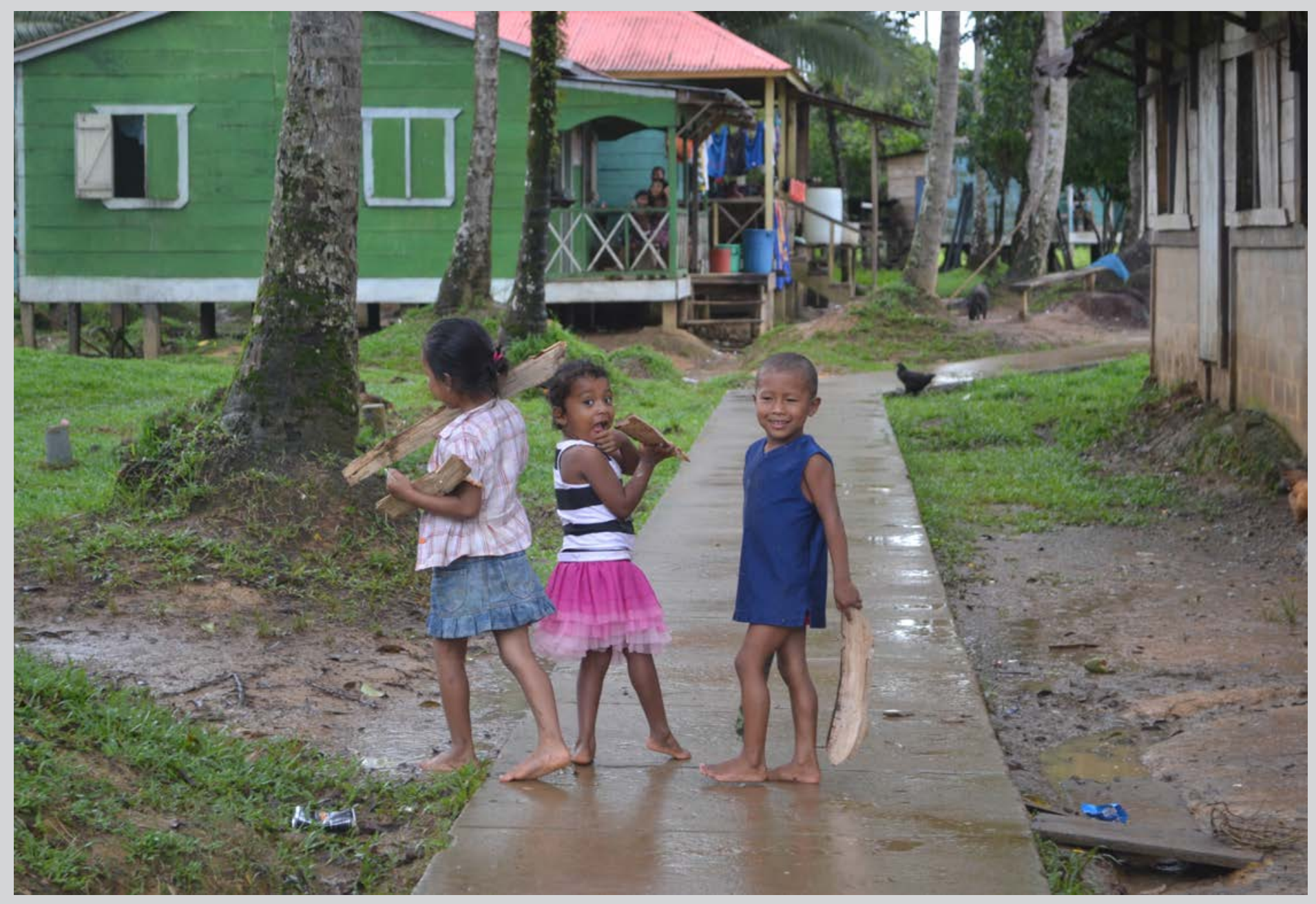

Comunidad de Wasakin, Territorio Tuahka, Municipio de Rosita, 2015 (Foto: Del Cid) 


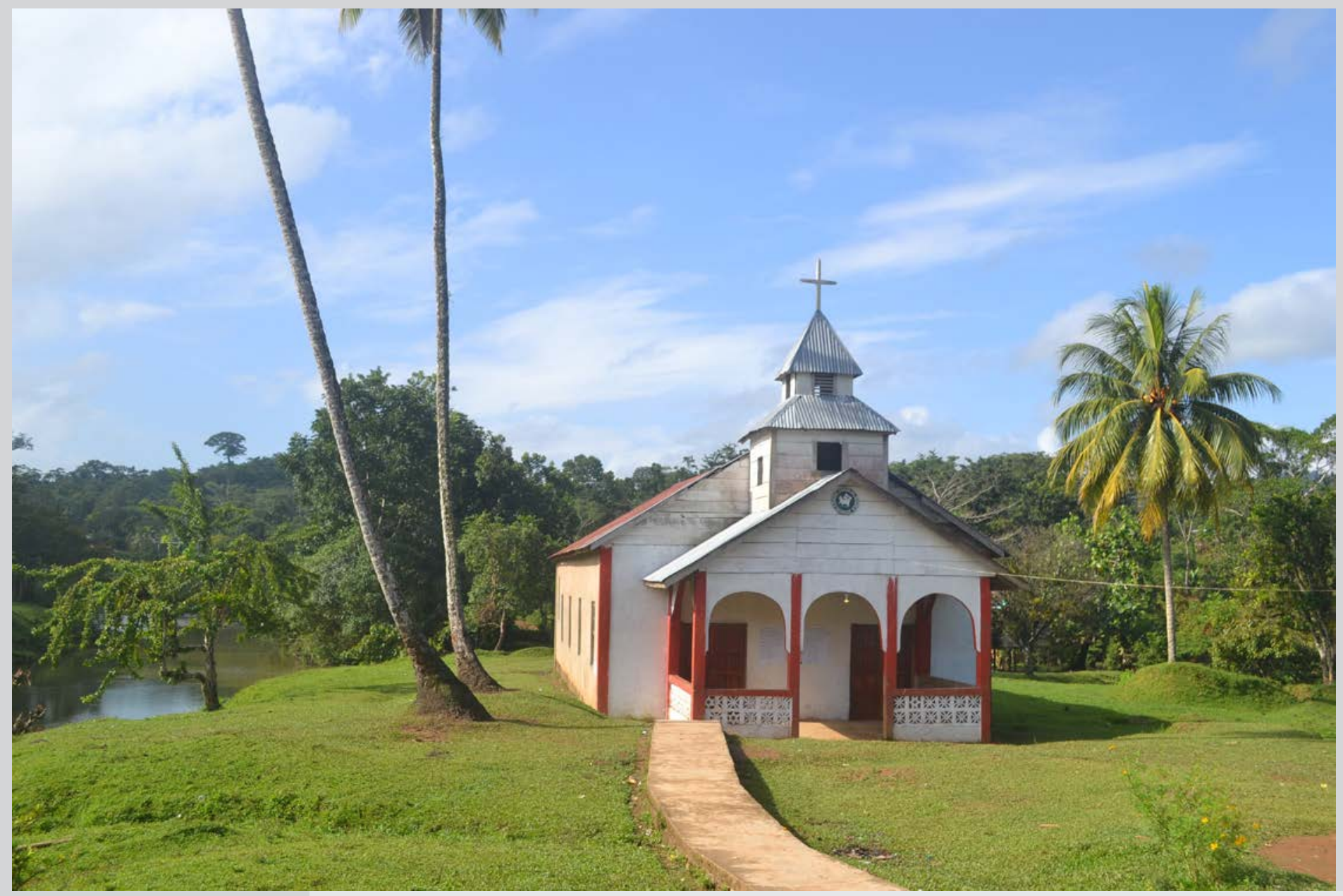

Iglesia Morava de Mahalwas, Territorio Mayangna Sauni Arungka, Municipio de Bonanza, 2015 (Foto: Del Cid) 